\title{
ANALISIS PENGARUH PENERAPAN BALANCED SCORECARD TERHADAP PENINGKATAN KINERJA PERUSAHAAN (STUDI KASUS PADA PERUSAHAAN DAERAH AIR MINUM (PDAM) LAMONGAN)
}

\author{
Ahmad Faishol \\ Fakultas Ekonomi, Universitas Islam Lamongan
}

\begin{abstract}
ABSTRAK
Dalam menghadapi lingkungan bisnis yang semakin kompleks seperti saat ini dibutuhkan metode pengukuran baru. Dalam hal ini metode yang dapat digunakan adalah Balanced Scorecard (BSC). Tujuan menggunakan Balanced Scorecard adalah untuk mengukur kinerja perusahaan dari empat perspektif yaitu : Perspektif Keuangan, Perspektif Pelanggan, Perspektif Proses Bisnis Internal, dan Perspektif pembelajaran dan perumbuhan. Penelitian dilakukan pada PDAM Kabupaten Lamongan yang bergerak dibidang penyedia air bersih, model penggukuran kinerja dengan Balanced Scorecard ini dipandang sesuai dengan pertimbangan bahwa konsep ini, menyeimbangkan kinerja financial dan non finansial. Tujuan dilakukannya penelitian ini adalah untuk mengetahui sejauh mana pengaruh penerapan BSC terhadap peningkatan kinerja perusahaan. Dengan menggunakan teknik penelitian tersebut ternyata penerapan balanced scorecard melalui empat perspektifnya dapat memberikan pengaruh yang cukup signifikan terhadap kinerja perusahaan.
\end{abstract}

Kata kunci : Kinerja, Balanced Scorecard

\section{PENDAHULUAN}

Kaplan dan Norton

menyatakan bahwa konsep balanced scorecard (BSC) dikembangkan untuk melengkapi pengukuran kinerja keuangan (atau dikenal dengan pengukuran tradisional) dan sebagai alat ukur yang cukup penting bagi organisasi perusahaan untuk merefleksikan pemikiran baru dalam era competitiveness dan efektivitas organisasi. Konsep ini memperkenalkan suatu sistem pengukuran kinerja perusahaan dengan menggunakan kriteria-kriteria tertentu yang merupakan penjabaran dari apa yang menjadi misi dan strategi perusahaan jangka panjang. Kriteria tersebut digolongkan menjadi empat perspektif yaitu: (1) perspektif keuangan, (2) perspektif Pelanggan, (3) perspektif proses bisnis internal, dan (4) perspektif pembelajaran dan pertumbuhan.

Melalui pengukuran keempat perspektif, manajemen perusahaan 
lebih mudah untuk mengukur kinerja dari unit bisnis saat ini dengan tetap mempertimbangkan kepentingan masa depan, mengukur apa yang telah diinvestasikan dalam pengembangan sumber daya manusia (Hansen dan Mowen, 2011). Balanced Scorecard mempunyai keunggulan dalam sistem perencanaan strategik diantaranya komprehensif, koheren, terukur dan seimbang (Mulyadi 2001 :18),

Tujuan penelitian ini adalah untuk mengetahui apakah ada pengaruh dari empat prespektif balanced scorecard terhadap peningkatan kinerja perusahaan dan untuk mengetahui empat perspektif balanced scorecard manakah yang mempunyai pengaruh paling dominan terhadap peningkatan kinerja perusahaan.

\section{TINJAUAN PUSTAKA}

\subsection{Kinerja Perusahaan}

Kinerja perusahaan adalah suatu tampilan keadaan secara utuh atas perusahaan selama periode waktu tertentu, merupakan hasil atau prestasi yang dipengaruhi oleh kegiatan operasional perusahaan dalam memanfaatkan sumber daya-sumber daya yang dimiliki (Helfert dalam Widodo, 2011 : 9).

\subsection{Balanced Scorecard}

Menurut (Hansen dan Mowen, 2011:366) Balanced Scorecard adalah sistem manajemen strategis yang mendefinisikan sisitem akuntansi pertanggungjawaban berdasarkan strategi. Balanced Scorecard menerjemahkan visi dan strategiorganisasi dalam tujuan operasional dan ukuran kinerja dalam empat perspektif, yaitu perspektif keuangan, perspektif pelanggan, perspektif proses bisnis internal, serta perspektif pembelajaran dan perumbuhan. Perspektif keuangan menjelaskan konsekuensi ekonomi tindakan yang diambil dalam tiga perspektif lain. Perspektif pelanggan mendefinisikan segmen pasar dan pelanggan dimana unit bisnis akan bersaing. Perspektif proses bisnis internal menjelaskan proses internal yang diperlukan untuk memberikan nilai pelanggan dan pemilik. Akhirnya, Perspektif pembelajaran dan partumbuhan mendefinisikan kemampuan yang diperlukan organisasi untuk memperoleh pertumbuhan jangka panjang dan perbaikan.

Oleh karena itu sangatlah penting untuk mengukur kinerja perusahaan berdasarkan ke-empat perspektif tersebut. Adapun penjelasan ke empat 
perspektif tersebut adalah sebagi berikut

a. Perspektif keuangan (Financial Perspective)

Menurut Gasperzs (2008:38), Penilaian kinerja keuangan dapat dijadikan indicator apakah strategi perusahaan, implementasi dan kepuasanya sudah memberikan perbaikan yang pengukuran keseluruhanya melalui prosentase rata-rata pertumbuhan pendapatan, dan rata-rata pertumbuhan penjualan dalam target market. Pengukuran kinerja keuangan dibagi menjadi 3 bagian yang akan digunakan yaitu : Growh (bertumbuh), (2) Sustain (bertahan), (3) Harvest (menunai).

\section{b. Perspektif Pelanggan}

Perspektif pelanggan adalah sumber komponen pendapatan dari tujuan keuangan, perspektif ini mendefinisikan dan memilih pelanggan dan segmen pasar dimana perusahaan memutuskan untuk bersaing (Hansen dan Mowen $2011: 371)$.

\section{c. Perspektif Proses Bisnis Internal}

Dalam perspektif ini para manajer melakukan identifikasi berbagai proses yang sangat penting untuk mecapai tujuan pelanggan dan pemegang saham.
Perusahaan akan menentukan tujuan dan ukuran-ukuran untuk perspektif ini setelah terlebih dahulu menentukan tujuan dan ukuran-ukuran pada perspektif keuangan dan pelanggan. pengukuran kinerja dalam perspektif proses bisnis internal menjadi 3 bagian yaitu : (1) proses inovasi, (2) proses operasi, (3) pelayanan purna jual.

d. Perspektif Pembelajaran dan Pertumbuhan

Proses belajar dan bertumbuh suatu organisasi bersumber dari tiga kategori (Kaplan dan Norton dalam Widodo,2011:49). Yaitu: people, system, dan organization procedure.

\section{METODOLOGI PENELITIAN}

Jenis penelitian yang digunakan oleh penulis adalah metode kuantitatif, yaitu untuk menggambarkan dan mengungkap suatu masalah, keadaan, peristiwa sebagaimana adanya atau menggungkap fakta secara lebih mendalam mengenai pengaruh penerapan balanced scorcecard erhadap peningkatan kinerja perusahaan,

Teknik yang digunakan dalam pengambilan sampel adalah teknik sampel probabilitas (probability sampling) yaitu dengan memilih sampel acak 
sederhana (simple random sampling). Metode pengumpulan data yang digunakan adalah wawancara, kuesioner dokumentasi. Operasional variablel meliputi variabel dependen: perspektif keuangan, pelanggan, proses bisnis internal, serta pembelajaran dan perumbuhan, variabel independen yaitu kinerja perusahaan.

\section{HASIL PENELITIAN DAN PEMBAHASAN}

\subsection{Uji Validitas dan Reliabilitas Instrumen Penelitian}

Variabel balanced scorecard yang diteliti dinyatakan valid dengan nilai koefisien korelasi pearson product moment $r_{\text {hitung }}>0,468$ sehingga seluruh indikator variabel dinyatakan valid sedangkan keseluruhan indikator dari variabel kinerja perusahaan yang diteliti dinyatakan valid dengan nilai koefisien korelasi pearson product moment $r_{\text {hitung }}>$ 0,468. Hal ini menunjukkan bahwa masing-masing butir pertanyaan pada variabel prestasi kerja adalah valid.

Pada Tabel 1 dapat diketahui bahwa keseluruhan variabel yang diteliti dinyatakan reliabel dengan nilai koefisien korelasi alpha cronbach > 0,6 maka dapat disimpulkan seluruh variabel dinyatakan reliabel.

Tabel 1. Hasil Uji Reliabilitas

\begin{tabular}{|l|r|r|}
\hline \multicolumn{1}{|c|}{ Variabel } & $\begin{array}{c}\text { Alfa- } \\
\text { Cronbach }\end{array}$ & Keterangan \\
\hline Balanced Scorecard (X) & & \\
\hline 1. Perspektif Keuangan (X1) & 0,968 & Reliabel \\
\hline 2. Perspektif Pelanggan (X2) & 0,966 & Reliabel \\
\hline 3. Perspektif Proses Bisnis Internal (X3) & 0,987 & Reliabel \\
\hline 4. Perspektif Pembelajaran dan Pertumbuhan (X4) & 0,984 & Reliabel \\
\hline Kinerja Perusahaan (Y) & 0,963 & Reliabel \\
\hline
\end{tabular}

\subsection{Uji Asumsi klasik}

\subsubsection{Uji Normalitas}

Dilihat dari hasil uji Kolmogorov Smirnov pada Tabel 2 menunjukkan nilai $p$-value sebesar 0,858 . Nilai $p$-value $>\alpha(0,858>0,050)$, maka dapat diambil keputusan untuk menerima hipotesis nol $\left(\mathrm{H}_{0}\right)$. Dengan demikian dapat disimpulkan bahwa residual berdistribusi normal. 
Tabel 2. One-Sampel Kolmogrov-Smirnov Test

\begin{tabular}{|l|l|r|}
\hline \multicolumn{2}{|l|}{} & \multicolumn{2}{|c|}{$\begin{array}{l}\text { Rnstandardized } \\
\text { Residual }\end{array}$} \\
\hline $\mathrm{N}$ & Mean & 18 \\
Normal Parameters & Sdt. & 0,0000000 \\
& Deviation & 1.715506557 \\
Most Extreme & Absolute & 0,143 \\
Differences & Positif & 0,143 \\
& Negative & $-0,119$ \\
Kolmogrov-Smirnov Z & & 0,605 \\
Asymp. Sig. (2-tailed) & & 0,858 \\
\hline
\end{tabular}

\subsubsection{Uji Heteroskedastisitas}

Jika dilihat Gambar 1, dapat kita ketahui bahwa scatterplot tidak membentuk pola yang teratur dan jelas.
Jadi, dapat disimpulkan bahwa pada persamaan regresi tidak terjadi heterokedastisitas.

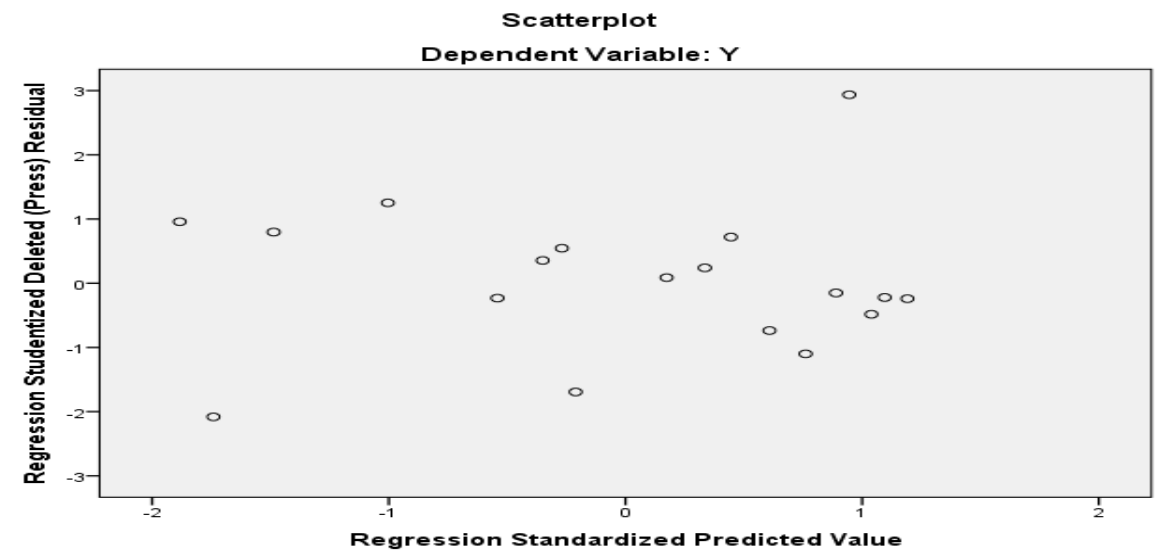

Gambar 1. Scatterplot

\subsubsection{Uji Multikolinieritas}

Table 3 menunjukkan bahwa hasil VIF lebih kecil dari angka 10 yang menunjukan tidak terjadi multiko.

Tabel 3. Multikolinieritas

Collinearrity Statistics

\begin{tabular}{|c|c|}
\hline Tolerance & VIF \\
\hline 0.337 & 2.964 \\
0.420 & 2.382 \\
0.485 & 2.964 \\
0.363 & 2.752 \\
\hline
\end{tabular}

4.3 Analisis Regresi Penerapan Balanced Scorecard terhadap

\section{Kinerja Perusahaan}

Berikut ini adalah persamaan regresi linier berganda yang memodelkan hubungan antara Penerapan Balanced Scorecard terhadap Kinerja Perusahaan PDAM Lamongan.

$$
\begin{aligned}
\mathrm{Y}= & 0,838+0,456 \mathrm{X} 1+0,212 \mathrm{X} 2 \\
& +0,108 \mathrm{X} 3+0,133 \mathrm{X} 4
\end{aligned}
$$


Variabel perspektif keuangan, pelanggan. Proses bisnisi internal, serta proses pertumbuhan dan pembelajaran berpengaruh positif terhadap kinerja perusahaan.
Tabel 4 menunjukkan nilai signifikansi 0,000 yang menunjukan nilai lebih kecil dari 0,05 , sehingga dapat disimpulkan variabel balanced scorecard berpengaruh signifikan terhadap peningkatan kinerja perusahaan.

Tabel 4. Hasil Uji F

\begin{tabular}{|l|r|c|c|c|c|}
\hline Model & \multicolumn{1}{|c|}{$\begin{array}{c}\text { Sum Of } \\
\text { Squares }\end{array}$} & Df & $\begin{array}{c}\text { Mean } \\
\text { Square }\end{array}$ & F & Sig \\
\hline Regression & 1824.887 & 4 & 456.222 & 118.482 & 0.000 \\
Residual & 50.057 & 13 & 3.851 & & \\
Total & 1874.944 & 17 & & & \\
\hline
\end{tabular}

Tabel 5 menunjukkan bahwa nilai signifikansi perspektif keuangan (X1) sebesar 0,000 , pelanggan 0,004 , prosen internal bisnis 0,042 , pembelajaran 0,029 maka semua variabel berpengaruh terhadap kinerja perusahaan. Sehingga dapat disimpulkan, bahwa perspektif keuangan adalah variabel yang lebih dominan pengaruhnya terhadap peningkatan kinerja perusahaan.

Tabel 5. Hasil Uji t

\begin{tabular}{|c|c|c|c|c|c|}
\hline \multirow{2}{*}{ Model } & \multicolumn{2}{|c|}{$\begin{array}{c}\text { Unstandardized } \\
\text { Coefficients }\end{array}$} & $\begin{array}{c}\text { Standardized } \\
\text { Coefficients }\end{array}$ & T & Sig \\
\cline { 2 - 4 } & B & Std. Error & Beta & & \\
\hline (constantant) & 0,838 & 2.080 & & 0,403 & 0,649 \\
X1 & 0,456 & 0,067 & 0,530 & 6,791 &, 000 \\
X2 & 0,212 & 0,059 & 0,249 & 3,556 &, 004 \\
X3 & 0,108 & 0,048 & 0,147 & 2,253 &, 042 \\
X4 & 0,133 & 0,054 & 0,184 & 2,454 &, 029 \\
\hline
\end{tabular}

\subsection{Koefisien Determinasi}

Nilai R menunjukkan angka sebesar 0,987 berarti berhubungan korelasi secara bersama-sama antara variabel independen dan variabel dependen sangat kuat karena $\mathrm{R}$ lebih besar dari 0,05 dan pengujian yang dilakukan dengan melihat R Square diperoleh nilai
0,973, yang berarti bahwa variabel bebas balanced scorecard berpengaruh terhadap variabel peningkatan kinerja perusahaan sebesar 97,3\%, sedangkan sisanya yaitu sebesar $2,7 \%$ dipengaruhi oleh faktor lain. 
Tabel 6. Hasil Uji Koefisien Determinasi

\begin{tabular}{|c|c|}
\hline $\mathbf{R}$ & R Square \\
\hline 0,987 & 0,973 \\
\hline
\end{tabular}

\subsection{Analisis Pengaruh Penerapan}

Balanced Scorecard terhadap Kinerja Perusahaan PDAM

\section{Lamongan}

Berdasarkan hasil uji $F$ variabel balanced scorecard berpengaruh terhadap peningkatan kinerja perusahaan dengan tingkat nilai signifikan sebasar 0,000 lebih kecil dari 0,05. Hal ini menunjukan bahwa $\mathrm{H}_{1}$ diterima dan $\mathrm{H}_{0}$ ditolak, bahwa balanced scorecard berpengaruh signifikan terhadap peningkatan kinerja perusahaan.

Dari hasil analisis menggunakan uji t, diketahui bahwa tingkat signifikansi variabel perspektif keuangan sebesar 0,000 , pelanggan 0,004 , proses internal bisnis 0,042 , setra pembelajaran dan pertumbuhan 0,363 maka semua perspektif berpengaruh terhadap peningkatan kinerja perusahaan. Dari hasil tersebut menunjukan bahwa variabel perspektif keauangan (X1) yang lebih dominan pengaruhnya terhadap peningkatan kinerjaa perusahaan $(\mathrm{Y})$.

\section{PENUTUP}

\subsection{Simpulan}

Baik perspektif keuangan, pelanggan, proses bisnis internal serta pembelajaran dan pertumbuhan mempunyai pengaruh yang cukup signifikan terhadap peningkatan kinerja perusahaan, artinya dengan adanya pengukuran strategis, tujuan serta program tindakan dari masing-masing perspektif dapat memberikan pengaruh terhadap peningkatan kinerja perusahaan PDAM Kabupaten Lamongan..

\subsection{Saran}

Diharapkan dengan terumuskanya strategi pengukuran dan program tindakan bisa diimplementasikan PDAM Kabupaten Lamongan agar dapat dipertahankan dan meningkatkan usahanya dimasa mendatang. Perlu dilakukan pengkajian lebih dalam kembali terhadap hasil-hasil yang telah dicapai serta upaya mengevaluasi kembali program tindakan yang telah dilakukan setelah periode implementasi dilaksanakan pada periode tertentu agar tujuan dari masing-masing perspektif dapat tercapai secara optimal 


\section{DAFTAR PUSTAKA}

Gaspersz, Vincent. 2008. Sistem Manajemen Kinerja Terintegrasi Balanced Scorecard dengan Six Sigma untuk Organisasi Bisnis dan Pemerintah. Jakarta : Gramedia Pustaka Umum.

Kaplan, R. S dan David P. N. 1996. Balanced Scorecard : Menerapkan Strategi Menjadi Aksi. Jakarta : Erlangga.

Mulyadi. 2001. Balanced Scorecard; Alat Manajemen Kontemporer Untuk Pelipatgandakan Kinerja Laporan Keuangan Perusahaan, Cetakan Kesatu. Jakarta : Penerbit Salemba Empat.

Hansen, Mayane dan Mowen. 2011. Akuntansi Manajerial, buku 2 edisi 8. Jakarta : Penerbit Salemba Empat.

Widodo, Imam, 2011. Analisis Penilaian

$$
\begin{array}{lrr}
\text { Kinerja Perusahaan } & \text { Dengan } \\
\text { Pendekatan } & \text { Balanced } & \text { Scorecard } \\
\text { Pada } \quad \text { PT } & \text { Jansen } \\
\text { Indonesia.Semarang : } & \text { FE } \\
\text { Universitas Diponegoro. } &
\end{array}
$$

